Raijmakers, N.J.H., Veer, A.J.E. de, Zwaan, R., Hofstede, J., Francke, A.L. Which patients die in their preferred place? A secondary analysis of questionnaire data from bereaved relatives.

\begin{tabular}{l|l} 
Postprint & 1.0
\end{tabular}

Version

Journal website http://journals.sagepub.com/doi/abs/10.1177/0269216317710383

Pubmed link https://www.ncbi.nlm.nih.gov/pubmed/28590159

DOI $10.1177 / 0269216317710383$

This is a NIVEL certified Post Print, more info at http://www.nivel.eu

\title{
Which patients die in their preferred place? A secondary analysis of questionnaire data from bereaved relatives.
}

\author{
RAIJMAKERS NJ, DE VEER AJ, ZWAAN R, HOFSTEDE JM, FRANCKE AL.
}

Background: Previous studies on factors influencing the place of death have focused on cancer patients dying at home. However, home is not always the preferred place.

Aim: To provide insight into the extent to which patients with various diseases die in their preferred place and into factors associated with dying in the preferred place.

Design: A secondary analysis of the dataset of the evaluation study of the National Quality Improvement Programme for Palliative Care was undertaken to explore factors related to 'dying in the preferred place'.

Setting/participants: 797 bereaved relatives filled in the CQ-index Palliative Care, a validated and reliable questionnaire.

Results: Two-thirds of the patients died in the preferred place. A preference for dying at home and having had a stroke decreased the likelihood of dying in the preferred place, while having a partner, dementia, contact with the GP in the last week before death, and continuity of care between professionals increased the likelihood of dying in the preferred place. Furthermore, people who wanted to die at home and also had dementia were more likely to die elsewhere than people without dementia who wanted to die at home. Conclusions: Positive associations were found between continuity of care between healthcare professionals and contact with the GP and the chance of people dying in their preferred place. Moreover, special attention for people who have had a stroke and for people with dementia who want to die at home seems indicated as their diagnosis is negatively associated with dying in their preferred place.

\section{What is already known about the topic?}

- Place of death is a quality indicator for palliative care 
Raijmakers, N.J.H., Veer, A.J.E. de, Zwaan, R., Hofstede, J., Francke, A.L. Which patients die in their preferred place? A secondary analysis of questionnaire data from bereaved relatives.

- Most studies have focused on factors influencing dying at home, instead of dying in the preferred place

- A substantial group of people are still not able to die in their preferred place.

\section{What this paper adds?}

- Preference for a home death is negatively associated with the likelihood of dying in the preferred place, even more for people with dementia.

- Continuity of care by different professionals and GP contact in the last week before death are positively associated with dying in the preferred place.

- People with a stroke less often die in the preferred place of death.

\section{Implications for practice, theory or policy?}

- The involvement of GPs in the last stage of life is crucial in helping the patient to die in the preferred place, especially to die at home.

- Healthcare professionals should cooperate closely to ensure continuity of care between different professionals. This is associated with the likelihood of dying in the preferred place.

- Special attention is needed for people who want to die at home after having a stroke or while having dementia. The support of their partners (if present) could be crucial, as partners play an important role in enabling the patient to die in the preferred place.

\section{INTRODUCTION}

Palliative care aims to control symptoms and to improve the quality of life of patients with a life-threatening disease and their relatives.[1] It has been suggested that the place of death is an indicator for the quality of palliative care. [2, 3] For many patients the preferred place of death is their home, followed by a palliative care unit or hospice. [4-6] Unfortunately, people do not always die in the preferred place; the congruence between the actual and preferred place of death varies between $66 \%$ and $91 \%$ in Europe. More specifically, the percentage of people who ultimately die in their preferred place is $83-91 \%$ in the Netherlands, $88 \%$ in Spain, 66-70\% in Italy and $71-81 \%$ in Belgium. $[2,5,7]$

There are many reasons why people are not able to die in the place they prefer; some of these might be unalterable, but others might be susceptible to change, such as a lack of contact with the GP in the last phase of life [8]. A wide body of evidence exists about factors that influence a home death, as extensively summarized by Gomes and Higginson. [9] Since the home is often assumed to be the preferred place of death $[4,10,11]$, most studies have focused on factors influencing dying at home. However, as already mentioned, home is not the preferred place for everybody. Therefore, palliative care practice and research might have to shift its focus from 'dying at home' to 'dying in the preferred place'.

An important condition for dying in the preferred place is that caregivers and professionals know what the preferred place of death is, which underlines the importance of communication and advance care planning. Previous research on factors that influence the likelihood of dying in the preferred place point in the direction of factors that are in line with factors related to dying at home, such as a 
Raijmakers, N.J.H., Veer, A.J.E. de, Zwaan, R., Hofstede, J., Francke, A.L. Which patients die in their preferred place? A secondary analysis of questionnaire data from bereaved relatives.

Palliative Medicine: 2018, 32(2), 347-356

cancer diagnosis [12] and control of symptoms.[13] Other known factors that increase the congruence between the preferred and actual place of death are enrolment in hospice care, physician support and family support. [6, 13, 14]. However, a substantial group of people are still not able to die in their preferred place. Therefore, more information about factors influencing dying in the preferred place of death is needed to develop strategies, both for care professionals and for patients and families, to further increase the likelihood that patients actually die in their preferred place, and by doing so, to improve the quality of palliative care. Therefore, we aim to improve insight into the determinants of dying in the preferred place among patients with various diseases. The research questions are:

- To what extent do patients die in their preferred place of death?

- Which factors are associated with dying in the preferred place for patients?

\section{METHODS}

\section{Description of the data and the population}

An existing set of questionnaire data was analysed, obtained in the evaluation study of the Dutch National Quality Improvement Programme for Palliative Care. [15] This programme (2012-2016) was open to all healthcare providers that seek to improve palliative care. The data concerned various care settings, including the patient's home, hospices, hospitals, nursing homes, homes for the elderly, home care organizations, and mental health care organizations. The term 'professional' is used in this study to refer to those working in these institutions, such as medical specialists, nursing-home doctors, nurses, psychotherapists, social workers, spiritual counsellors and others. The data used was provided by bereaved relatives, as the place of death could only be indicated after the patient had died.

For this article, we used data reported by bereaved relatives regarding the quality of palliative care and gathered in the first 17 months of the evaluation of the aforementioned quality improvement programme. All relatives whose data we analysed were relatives of patients who died after an illness between six weeks and six months previously. Data from the bereaved relatives of patients who died suddenly and unexpectedly were excluded. The bereaved relatives (e.g. partners, children or other family members) had been the intermediary for a patient and the professionals, and had been involved in the care of that patient. The professionals participating in the quality improvement programme collected the names and addresses of the bereaved relatives who met the inclusion criteria (e.g. via registration systems within their care organizations, or via medical records). The bereaved relatives were sent an anonymous postal questionnaire (see below). Two weeks later, a reminder was sent if applicable. After elimination of the questionnaires from relatives that met the exclusion criteria the net response rate was $57 \%$.

\section{Questionnaire}

The data were collected with the validated Consumer Quality Index Palliative Care (CQ-index) for bereaved relatives. This questionnaire assesses the experiences of bereaved relatives with the palliative care that they and the patient received in the last week of life. It provides insight into their experience of control over and coordination of palliative care, the physical, psychosocial and spiritual care received, and the actual and preferred place of death.[15] The questionnaire consists of 64 
Raijmakers, N.J.H., Veer, A.J.E. de, Zwaan, R., Hofstede, J., Francke, A.L. Which patients die in their preferred place? A secondary analysis of questionnaire data from bereaved relatives.

Palliative Medicine: 2018, 32(2), 347-356

questions in total.[16] Based on an extensive literature search about the place of death of patients who died non-suddenly [17], we selected relevant items from this questionnaire, presented in Box 1. Additionally, information about the background characteristics (e.g. sex and age) of both the deceased patient and the relative as reported by the bereaved relatives in the questionnaire were included in the analysis.

\section{[BOX 1]}

\section{Data analysis}

Descriptive statistics were used to get overall percentages. To answer the first research question, the extent to which patients died in their preferred place, the correspondence between the preferred place of death and whether the patient died there was explored using logistic regression analyses for each category of preferred place separately (i.e. home, home for the elderly, hospice or palliative unit, nursing home, hospital, institution for mental health care, institution for mentally disabled). Proportions and the exact binomial 95\% confidence interval (CI) were calculated. As dying in the preferred place of death is a dichotomous variable, logistic regression analysis was also used to analyse the associations between the factors and the dependent variable 'dying in the preferred place' (the second research question). The factor preferred place was included as a factor, using home for the elderly as a reference category, as this preference was most favourable regarding dying in the preferred place $(92 \%)$.

First, univariate regression analyses were done for each factor. For the univariate analysis, a cut-off point of $\mathrm{p}=0.10$ (90\% CI does not include 1$)$ was used to determine which factors were significantly associated with dying in the preferred place. These significant factors were then included in a multivariate regression analysis.

The second step was to explore multicollinearity and how these remaining factors were related to the preferred place of death using contingency tables with a chisquare test of independence. There was no indication of multicollinearity. Cases of dying in a nursing home or hospital were left out in the multivariate model, because there was hardly any variance to be explained, i.e. almost all patients with a preference for a nursing home or a hospital also died there. Furthermore, respondents whose loved one died in an institution for mental health care, mentally disabled or other kind of institution $(n=26)$ were also left out because of the particular context in which they died. Factors with a statistically significant association $(p<0.05)$ with the preferred place of dying were entered one by one as interaction terms in a multivariate regression analysis with the remaining factors in step 1. If the odds ratio of the interaction term was related to the outcome variable (dying in the preferred place), the interaction term was entered in the multivariate model. Again, a cut-off point of $\mathrm{p}=0.10$ was used. This procedure led to three interaction terms. In the third step the factors and interaction terms were entered in a logistic regression analysis (backward stepwise). Because the multivariate analysis removes cases with missing values, we tested the model again excluding the non-significant factors and therefore including more cases.

The cut-off point that was used for generating the multivariate model was $\mathrm{p}=0.05$. The Nagelkerke $\mathrm{R}^{2}$ for the multivariate model was used to measure the extent to which the model explains the variance in dying in the preferred place. The HosmerLemeshow test was used to measure how well the model fits the data. The analysis 
Raijmakers, N.J.H., Veer, A.J.E. de, Zwaan, R., Hofstede, J., Francke, A.L. Which patients die in their preferred place? A secondary analysis of questionnaire data from bereaved relatives.

Palliative Medicine: 2018, 32(2), 347-356

was carried out using the computer program Statistical Package for the Social Sciences (SPSS), version 18.0 for Windows.

\section{Ethical considerations}

The rules stipulated in the Dutch Personal Data Protection Act (Wet Bescherming Persoonsgegevens) were taken into account in this study. All personal identifiers were removed or disguised in the process of analysis to safeguard the privacy and anonymity of the participants. Furthermore, the study protocol of the evaluation of the Dutch National Quality Improvement Programme for Palliative Care has been approved by the Medical Ethical Committee of the University Medical Center in Leiden, the Netherlands. The bereaved relatives were informed in an information letter accompanying the questionnaire about the fact that the questionnaire data could be used for additional analyses.

\section{RESULTS}

\section{Respondents}

A total of 1013 bereaved relatives filled in the questionnaire (response rate of 57\%). The deceased patients in the response group did not differ from the deceased patients in the non response group with respect to age (means 80.5 and 80.4 years old, $\mathrm{F}=0.02, \mathrm{p}=.875$ ) and gender (female $53.8 \%$ and $57.3 \%$, chi-square $=2.19, \mathrm{p}=.138$ ). The analyses were based on the data of those relatives who both filled in the place of death and knew whether this was the preferred place of death. This was the case for 797 bereaved relatives. As shown in Table 1, the majority of the respondents were women $(69.3 \%)$, and the age category mode was 55-64 (32.3\%). Most of the bereaved relatives were the children $(49.4 \%)$ or partner/spouse $(37.3 \%)$ of the deceased patient.

\section{[TABLE 1][TABLE 2]}

Characteristics of the deceased patients and the palliative care they received Of the deceased patients, about half were female (53.6\%) (Table 2). The majority were aged 75 or older $(72.8 \%)$ and over one-third of the deceased patients had a partner (37.3\%). Most deceased patients had cancer $(43.7 \%)$ or dementia $(26.5 \%)$. Fatigue was the most prevalent symptom $(91.2 \%)$, followed by pain $(70.4 \%)$. Half of the patients had been in contact with a general practitioner (GP) in the last week before death $(56.5 \%)$. Bereaved relatives were most positive about the extent to which professionals took the personal wishes of the patient into account $(93.4 \%$ gave a positive assessment). Furthermore, $84.9 \%$ gave a positive assessment about the extent to which professionals knew how the patient thought about end-of-life decisions.

\section{[TABLE 3]}

\section{Dying in the preferred place}

Two-thirds of the patients $(69 \%, \mathrm{n}=551)$ died in the preferred place. However, the likelihood of dying in the preferred place depended on where they preferred to die 
Raijmakers, N.J.H., Veer, A.J.E. de, Zwaan, R., Hofstede, J., Francke, A.L. Which patients die in their preferred place? A secondary analysis of questionnaire data from bereaved relatives.

Palliative Medicine: 2018, 32(2), 347-356

(Table 3). A preference for a home death decreased the likelihood of dying in the preferred place (proportion $.59,95 \%$ CI .54-.63), whereas patients who preferred to die in a home for the elderly (proportion .92, 95\% CI .85-.96), in a hospice or palliative care unit (proportion .80, 95\% CI .69-.89), or in a nursing home (proportion .98, 95\% CI .90-1.00) were more likely to die in their preferred place.

\section{[TABLE 4]}

\section{Factors associated with dying in the preferred place: results of univariate analysis}

Table 4 lists the results of the univariate analysis of all factors in relation to dying in the preferred place. In total, 12 factors were associated with the likelihood of dying in the preferred place. Factors that increase the likelihood of dying in the preferred place were having a partner, having cancer, having had contact with a GP in the last week before death, a high level of expertise among the healthcare professionals, continuity of care, professionals' awareness of the patient's thoughts on end-of-life matters and taking the personal wishes of the patient into account. Factors that decrease this likelihood were being over 75 , being religious, having a stroke, having dementia, and the inability to control symptoms of a depressive nature.

\section{[TABLE 5]}

\section{Factors associated with dying in the preferred place: results of the multivariate analysis}

In the multivariate analysis, the following factors still associated with the likelihood of dying in the preferred place; patients with a partner, who had contact with their GP in the last week before death, and whose bereaved relatives experienced high continuity of care were more likely to die in the preferred place (Table 5). In the multivariate analyses, patients with dementia had a greater chance of dying in the preferred place (OR 0.14; 95\% CI 0.04-0.56). However, patients with dementia who wanted to die at home had a smaller chance of dying there (interaction effect, chisquare $(1)=65.386, p<.001)$. Furthermore, patients with dementia who wanted to die in a hospice or home for the elderly had the same chance of dying there as patients without dementia (chi-square $(1)=2.209, \mathrm{p}=.137$ ). In general, patients who wanted to die at home were less likely than others to die there, but the likelihood of dying at home increased if the GP visited them in the last week before their death (interaction effect, chi-square $(1)=245.457, \mathrm{p}<.000)$. If they wanted to die in a hospice or home for the elderly, the relationship between GP contact and dying there was less strong (chi-square $(1)=5.715, p=.017)$. The explained variance of the model is $56 \%$; in other words $56 \%$ of the variance in dying in the preferred place can be explained by these factors.

\section{DisCussion}

Preference for a home death decreases the likelihood of dying in the preferred place. Furthermore, people with a partner or with dementia were more likely to die in the preferred place. However, people with dementia who wanted to die at home were more likely to die elsewhere than people without dementia who wanted to die at home. 
Raijmakers, N.J.H., Veer, A.J.E. de, Zwaan, R., Hofstede, J., Francke, A.L. Which patients die in their preferred place? A secondary analysis of questionnaire data from bereaved relatives.

Palliative Medicine: 2018, 32(2), 347-356

In addition, people with a stroke were less likely to die in the preferred place of death. Other factors that were positively associated with dying in the preferred place for patients with various diseases were continuity of care by different professionals and GP contact in the last week before death. The latter is particularly important for people who wanted to die at home.

Most people wanted to die at home, but this preference for a home death decreased the likelihood of dying in the preferred place. This is consistent with previous studies that stated that patients with a preference for dying at home had a decreased likelihood of dying in their preferred place. $[12,18]$ However, the percentages of deaths in the preferred place for people with a preference for dying in a hospital (100\%), a nursing home (98.2\%), a home for the elderly (92.0\%) or an institution for the mentally disabled $(85.7 \%)$ are very high. These high percentages can be explained by the fact that these patients had already been admitted to these institutions and their preferences were shaped by the situation they were in. Especially when a person is living in a home for the elderly or a nursing home, this might feel like home and become the place where one would like to die. This could explain why people with dementia (who, in the Netherlands, often reside in a nursing home at the end of their life) were more likely to die in the preferred place.

The overall percentage of deaths in the preferred place was $68.7 \%$; this is lower than the percentages of between $83 \%$ and $88 \%$ for deaths in the preferred place reported by earlier studies conducted in the Netherlands.[2, 7, 8, 19] This could be a result of the fact that this study was carried out among bereaved relatives of patients with various diseases, whereas earlier studies mainly covered cancer patients; a cancer diagnosis is associated with a greater likelihood of dying in the preferred place.[12] It is noteworthy that, at the univariate level, our analysis showed that cancer patients were more likely to die in the preferred place than patients with dementia and organ failure diagnosis. This might be explained by differences in illness trajectories between cancer patients and non-cancer patients: the course of non-cancer illnesses is generally harder to predict, especially for organ failure, and death can come rather unexpectedly [20]. However, in the multivariate analyses a cancer diagnosis did not appear as a significant factor influencing dying in the preferred place. This might be explained by the fact that in this current study we had data on cancer patients who were relatively young and had a partner, both factors that contribute to dying in the preferred place. Having a partner who knows where the patient wants to die can help to achieve this. This emphasizes the importance of having end-of-life conversations about the preferences and wishes of the patient. In other words, advance care planning is important. Furthermore, partners often provide informal care for their beloved one and their efforts seem important in achieving a home death where this is the preference. However, we did not find an interaction effect between wanting to die at home and having a partner.

Our final model also included GP contact in the last week before death; this relationship between GP contact and place of death is strongest for people with a preference for a home death. Other research also identified provision of palliative care by the GP as a factor associated with a congruence between the actual and preferred place of death.[8] The causality of this relationship, however, needs to be further investigated.. Coordination between all professionals involved is important, 
Raijmakers, N.J.H., Veer, A.J.E. de, Zwaan, R., Hofstede, J., Francke, A.L. Which patients die in their preferred place? A secondary analysis of questionnaire data from bereaved relatives.

Palliative Medicine: 2018, 32(2), 347-356

as this is also associated with dying in the preferred place. To our knowledge, niver continuity of care by different professionals has not been identified earlier as a factor affecting the likelihood of dying in the preferred place, making this factor an addition to existing knowledge.

\section{Strengths and limitations of the study}

The large dataset used contains unique information regarding end-of-life care for patients with various diseases in various healthcare settings from the perspective of the bereaved relatives. A large number of bereaved relatives were included in the analysis $(n=797)$, giving the results statistical power, although the response rate of $57 \%$ might introduce a sampling bias. [21]

However, a limitation of using this existing dataset is that some factors known to influence the likelihood of dying in the preferred place (such as the patient's functional dependence upon others $[9,14]$ ) were not represented in the dataset. Therefore, the validity of the model might be lower than it would have been if all factors from the literature had been explored. Further research is needed to find more factors associated with dying in the preferred place and confirm the factors in this study.

Moreover, this study was based on the reports of bereaved relatives on the preferred place of death of the patient. The patients themselves would have been the most reliable source of information about preferred place of death, as it concerns them, but for ethical and practical reasons it is difficult to expose terminally ill patients to questions about their preferred place of death. Asking patients about the preferred place of death in earlier stages can be done, but preferences can changes in the last days of life. Bereaved relatives might have a good overview of the care preferences in the period shortly before death, making the relatives an important source of information.[22]

\section{Practical implications}

Enabling patients to die in their preferred place is a challenge, especially for people who have had a stroke or people with dementia and a preference for a home death. For these patients, the support of the patient's partner (if present) could be crucial, as partners play an important role in enabling the patient to die in the preferred place. Furthermore, we recommend the involvement of GPs in the last stage of life as a way of helping the patient to die in the preferred place. Moreover, healthcare professionals should realize that continuity of care between different professionals increases the likelihood of dying in the preferred place, which requires close cooperation.

\section{CONCLUSIONS}

In conclusion, our data indicates that continuity of care between different healthcare professionals and GP contact in the last week before death are important factors in relation to people dying in their preferred place. Special attention seems needed for people who have had a stroke and for people with dementia who want to die at home, as their diagnosis is negatively associated with dying in the preferred place. Taking 
Raijmakers, N.J.H., Veer, A.J.E. de, Zwaan, R., Hofstede, J., Francke, A.L. Which patients die in their preferred place? A secondary analysis of questionnaire data from bereaved relatives.

Palliative Medicine: 2018, 32(2), 347-356

these factors into account might contribute to an increase of the likelihood of people dying in their preferred place, an important marker of quality of palliative care.

\author{
Abbreviations \\ CQ Index: Consumer quality index \\ CI: confidence interval \\ OR: odds ratio \\ SPSS: Statistical Package for the Social Sciences \\ WMO: Medical-scientific Research on Humans Act \\ GP: General practitioner
}

\title{
Acknowledgements
}

ZonMw, The Netherlands Organization for Health Research and Development, financially supported the evaluation of the Dutch National Quality improvement Programme for Palliative Care (2012-2016), on which this database is based. We would like to thank Lucas van de Hoek for his statistical advice and Facit for the coordination of the data collection and data entry.

\section{Competing interests}

The authors declare that they have no competing interests.

\section{Authors' contributions}

$\mathrm{NR}, \mathrm{RZ}$ and AdV conducted the analysis and drafted the manuscript. AF and JH participated in the design of the analysis and gave comments on drafts of the manuscript. All authors read and approved the final manuscript.

\section{References}

1. Davies, E. and I.J. Higginson, Palliative care: the solid facts. 2004, World Health Organization: Geneva.

2. De Roo, M.L., et al., Actual and preferred place of death of home-dwelling patients in four European countries: making sense of quality indicators. PLoS One, 2014. 9(4): p. e93762.

3. NHS, End of Life Care Strategy. Promoting high quality care for all adults at the end of life. 2008.

4. Higginson, I.J. and G.J. Sen-Gupta, Place of care in advanced cancer: a qualitative systematic literature review of patient preferences. J Palliat Med, 2000. 3(3): p. 287-300.

5. Beccaro, M., et al., Actual and preferred place of death of cancer patients. Results from the Italian survey of the dying of cancer (ISDOC). J Epidemiol Community Health, 2006. 60(5): p. 412-6.

6. Brogaard, T., et al., Congruence between preferred and actual place of care and death among Danish cancer patients. Palliat Med, 2013. 27(2): p. 155-64.

7. Meeussen, K., et al., End-of-life care and circumstances of death in patients dying as a result of cancer in Belgium and the Netherlands: a retrospective comparative study. $J$ Clin Oncol, 2011. 29(32): p. 4327-34.

8. Ko, W., et al., Factors associated with fulfilling the preference for dying at home among cancer patients: the role of general practitioners. J Palliat Care, 2014. 30(3): p. 14150.

9. Gomes, B. and I.J. Higginson, Factors influencing death at home in terminally ill patients with cancer: systematic review. BMJ, 2006. 332(7540): p. 515-21. 
Raijmakers, N.J.H., Veer, A.J.E. de, Zwaan, R., Hofstede, J., Francke, A.L. Which patients die in their preferred place? A secondary analysis of questionnaire data from bereaved relatives.

Palliative Medicine: 2018, 32(2), 347-356

10. Gomes, B., et al., Heterogeneity and changes in preferences for dying at home: a systematic review. BMC Palliat Care, 2013. 12: p. 7.

11. Hoare, S., et al., Do Patients Want to Die at Home? A Systematic Review of the UK Literature, Focused on Missing Preferences for Place of Death. PLoS One, 2015. 10(11): p. e0142723.

12. Billingham, M.J. and S.J. Billingham, Congruence between preferred and actual place of death according to the presence of malignant or non-malignant disease: a systematic review and meta-analysis. BMJ Support Palliat Care, 2013. 3(2): p. 144-54.

13. Bell, C.L., E. Somogyi-Zalud, and K.H. Masaki, Factors associated with congruence between preferred and actual place of death. J Pain Symptom Manage, 2010. 39(3): p. 591-604.

14. Tang, S.T. and R. McCorkle, Determinants of congruence between the preferred and actual place of death for terminally ill cancer patients. J Palliat Care, 2003. 19(4): p. 230-7.

15. Raijmakers, N.J., et al., The effect and process evaluations of the national quality improvement programme for palliative care: the study protocol. BMC Palliat Care, 2014. 13(1): p. 5.

16. Claessen, S.J., et al., Measuring relatives' perspectives on the quality of palliative care: the Consumer Quality Index Palliative Care. J Pain Symptom Manage, 2013. 45(5): p. $875-84$.

17. Zwaan, R., Factors associated with dying at the patient's preferred place. A secondary analysis based on data reported by bereaved relatives. 2015, NIVEL/Free University: Utrecht/Amsterdam.

18. Agar, M., et al., Preference for place of care and place of death in palliative care: are these different questions? Palliat Med, 2008. 22(7): p. 787-795.

19. Koekoek, B., Regie over de plaats van sterven, in Bestuurs- en Organisatiewetenschap. 2014, University of Utrecht: Apeldoorn.

20. Lynn, J. and D.M. Adamson, Living well at the end of life. Adapting health care to serious chronic illness in old age. 2003, RAND Health: Santa Monica.

21. Lash TL, F.M., Fink AK, Applying Quantitative Bias Analysis to Epidemiologic Data. . Statistics for Biology and Health, ed. K.K. Gail M, Samet J , Tsiatis A, Wong W. 2009, New York: NY: Springer New York.

22. Rhodes, R.L., et al., Bereaved family members' evaluation of hospice care: what factors influence overall satisfaction with services? J Pain Symptom Manage, 2008. 35(4): p. 365-71. 
Raijmakers, N.J.H., Veer, A.J.E. de, Zwaan, R., Hofstede, J., Francke, A.L. Which patients die in their preferred place? A secondary analysis of questionnaire data from bereaved relatives.

Palliative Medicine: 2018, 32(2), 347-356

\section{BOX AND TABLES}

\begin{tabular}{|c|c|c|}
\hline \multicolumn{3}{|c|}{ Box 1: variables used from CQ-index for bereaved relatives } \\
\hline Variable & Question in the CQ-index & Answer categories \\
\hline $\begin{array}{l}\text { Dying in the } \\
\text { preferred place }\end{array}$ & $\begin{array}{l}\text { "Did your relative die in the } \\
\text { preferred place?" }\end{array}$ & $\begin{array}{l}\text { No, yes, I don't know } \\
\text { 'I don't know' was recoded as a missing } \\
\text { value in the dataset. }\end{array}$ \\
\hline $\begin{array}{l}\text { Preferred place of } \\
\text { death }\end{array}$ & $\begin{array}{l}\text { "Where did your relative prefer } \\
\text { to die?" }\end{array}$ & $\begin{array}{l}\text { Home, hospital, palliative unit in hospital, } \\
\text { nursing home, palliative unit in nursing } \\
\text { home, home for the elderly, palliative unit } \\
\text { in home for the elderly, high care hospice, } \\
\text { low care hospice, institution for the } \\
\text { mentally ill, institution for mental health } \\
\text { care, other institution, I don't know. } \\
\text { 'I don't know' was recoded as a missing } \\
\text { value in the dataset. In the analyses, } \\
\text { palliative unit in hospital, palliative unit in } \\
\text { nursing home, palliative unit in home for } \\
\text { the elderly, high care hospice, and low care } \\
\text { hospice were combined to make one } \\
\text { category. }\end{array}$ \\
\hline Role of a GP & $\begin{array}{l}\text { "From which professionals did } \\
\text { your relative receive care in the } \\
\text { last week before death?" }\end{array}$ & One category was 'GP' \\
\hline $\begin{array}{l}\text { Professionals had } \\
\text { necessary expertise }\end{array}$ & $\begin{array}{l}\text { "Did the professionals have the } \\
\text { necessary expertise?" }\end{array}$ & $\begin{array}{l}\text { none, some, most, all. } \\
\text { Answers were dichotomized into } 1=\text { yes } \\
\text { (most or all) or } 0=\text { no (none or some). }\end{array}$ \\
\hline $\begin{array}{l}\text { Professionals were } \\
\text { informed about } \\
\text { patient's views on } \\
\text { end-of-life decisions }\end{array}$ & $\begin{array}{l}\text { "Did the professionals ask for } \\
\text { your relative's thoughts on end- } \\
\text { of-life matters (palliative } \\
\text { sedation, stopping life } \\
\text { prolongation treatment, } \\
\text { increasing pain medication } \\
\text { with possible life-shortening } \\
\text { effect)?" }\end{array}$ & $\begin{array}{l}\text { no, yes, don't know. } \\
\text { Answers were dichotomized into } 1=\text { yes or } \\
0=\text { no (no or don't know). }\end{array}$ \\
\hline $\begin{array}{l}\text { Professional support } \\
\text { with preparations for } \\
\text { saying goodbye to } \\
\text { relatives }\end{array}$ & $\begin{array}{l}\text { 'Did your relative receive } \\
\text { support from the professional } \\
\text { with preparations for saying } \\
\text { goodbye to relatives?' }\end{array}$ & $\begin{array}{l}\text { never, sometimes, usually, always, not } \\
\text { applicable. } \\
\text { Answers were dichotomized into } 1=\text { yes } \\
\text { (usually or always) or } 0=\text { no (never, } \\
\text { sometimes, not applicable). }\end{array}$ \\
\hline $\begin{array}{l}\text { Continuity in care by } \\
\text { different } \\
\text { professionals }\end{array}$ & $\begin{array}{l}\text { Was there a good match } \\
\text { between the care provided by } \\
\text { the different professionals } \\
\text { involved in looking after you? }\end{array}$ & $\begin{array}{l}\text { never, sometimes, usually, always. } \\
\text { Answers were dichotomized into } 1=\text { yes } \\
\text { (usually or always) or } 0=\text { no (never or } \\
\text { sometimes). }\end{array}$ \\
\hline $\begin{array}{l}\text { Professionals took } \\
\text { the personal wishes } \\
\text { of the patient into } \\
\text { account }\end{array}$ & $\begin{array}{l}\text { 'Did the professionals take the } \\
\text { personal wishes of your relative } \\
\text { into account?' }\end{array}$ & $\begin{array}{l}\text { none, some, most, all. } \\
\text { Answers were dichotomized into } 1=\text { yes } \\
\text { (most or all) or } 0=\text { no (none or some). }\end{array}$ \\
\hline
\end{tabular}


Raijmakers, N.J.H., Veer, A.J.E. de, Zwaan, R., Hofstede, J., Francke, A.L. Which patients die in their preferred place? A secondary analysis of questionnaire data from bereaved relatives.

Table 1: Characteristics of bereaved relatives (respondents) $(\mathrm{n}=797 *)$

\begin{tabular}{|l|l|}
\hline & $\mathbf{N}(\mathbf{\%})$ \\
\hline Sex $(\mathrm{n}=795)$ & \\
\hline Man & $244(30.7 \%)$ \\
\hline Age $(\mathrm{n}=796)$ & $551(69.3 \%)$ \\
\hline $25-34$ & $8(1.0 \%)$ \\
\hline $35-44$ & $30(3.8 \%)$ \\
\hline $45-54$ & $163(20.5 \%)$ \\
\hline $55-64$ & $257(32.3 \%)$ \\
\hline $65-74$ & $208(26.1 \%)$ \\
\hline $75+$ & $130(16.3 \%)$ \\
\hline Relationship to patient $(\mathrm{n}=794)$ & \\
\hline Spouse/partner & $299(37.7 \%)$ \\
\hline Son/daughter & $392(49.4 \%)$ \\
\hline Family other than partner or child & $77(9.7 \%)$ \\
\hline Other/not family & $26(3.3 \%)$ \\
\hline$*$ The number of observations varies per variable due to missing data \\
\hline \multicolumn{2}{|l}{} \\
\hline \multicolumn{2}{|l}{}
\end{tabular}


Raijmakers, N.J.H., Veer, A.J.E. de, Zwaan, R., Hofstede, J., Francke, A.L. Which patients die in their preferred place? A secondary analysis of questionnaire data from bereaved relatives.

\begin{tabular}{|c|c|}
\hline \multicolumn{2}{|l|}{$\begin{array}{l}\text { Table 2: Characteristics of dec } \\
\text { Individual factors of patients }\end{array}$} \\
\hline \multicolumn{2}{|l|}{$\operatorname{Sex}(n=797)$} \\
\hline Man & $372(46.7 \%)$ \\
\hline Woman & $425(53.3 \%)$ \\
\hline \multicolumn{2}{|l|}{ Age $(n=776)$} \\
\hline$<75$ & $211(27.2 \%)$ \\
\hline $75+$ & $565(72.8 \%)$ \\
\hline Being religious $(n=785)$ & $547(69.7 \%)$ \\
\hline \multicolumn{2}{|l|}{ Environmental factors } \\
\hline Having a partner $(n=794)$ & $299(37.3 \%)$ \\
\hline \multicolumn{2}{|l|}{ Level of education of bereaved relative $(n=291)$} \\
\hline Low & $198(68.0 \%)$ \\
\hline Middle & $49(16.8 \%)$ \\
\hline High & $44(15.1 \%)$ \\
\hline Good health of bereaved relative $(n=791)$ & $679(85.8 \%)$ \\
\hline \multicolumn{2}{|l|}{ Illness-related factors } \\
\hline \multicolumn{2}{|l|}{ Diagnoses $(n=796)$} \\
\hline Cancer & $348(43.7 \%)$ \\
\hline Stroke & $102(12.8 \%)$ \\
\hline COPD & $87(10.9 \%)$ \\
\hline Heart failure & $116(14.6 \%)$ \\
\hline Dementia & $211(26.5 \%)$ \\
\hline \multicolumn{2}{|l|}{ Presence of symptoms in week before death } \\
\hline Pain $(n=716)$ & $503(70.3 \%)$ \\
\hline Fatigue $(\mathrm{n}=725)$ & $661(91.2 \%)$ \\
\hline Shortness of breath $(n=691)$ & $429(62.1 \%)$ \\
\hline Constipation $(\mathrm{n}=639)$ & $277(43.3 \%)$ \\
\hline Depressive mood $(\mathrm{n}=686)$ & $425(62.0 \%)$ \\
\hline Anxiety $(\mathrm{n}=687)$ & $401(58.4 \%)$ \\
\hline \multicolumn{2}{|l|}{ Care as perceived by bereaved relative } \\
\hline Patient had GP contact in week before death $(n=797)$ & $450(56.5 \%)$ \\
\hline Professionals had necessary expertise $(\mathrm{n}=788)$ & $718(91.1 \%)$ \\
\hline $\begin{array}{l}\text { Professionals were informed about patient's views regarding } \\
\text { end-of-life decisions }(\mathrm{n}=649)^{* *}\end{array}$ & $551(84.9 \%)$ \\
\hline $\begin{array}{l}\text { Professional support with preparations for saying goodbye to } \\
\text { relatives }(\mathrm{n}=478)^{* *}\end{array}$ & $409(85.6 \%)$ \\
\hline Continuity in care by different professionals $(n=773)$ & $701(90.7 \%)$ \\
\hline $\begin{array}{l}\text { Professionals took the personal wishes of the patient into } \\
\text { account }(n=786)\end{array}$ & $734(93.4 \%)$ \\
\hline \multicolumn{2}{|c|}{$\begin{array}{l}\text { * The number of observations varies per variable due to missing data } \\
\text { **The answer category 'I don't know' was marked as missing }\end{array}$} \\
\hline
\end{tabular}


Raijmakers, N.J.H., Veer, A.J.E. de, Zwaan, R., Hofstede, J., Francke, A.L. Which patients die in their preferred place? A secondary analysis of questionnaire data from bereaved relatives.

Palliative Medicine: 2018, 32(2), 347-356

Table 3: Preferred and actual place of death $(n=797)$

\begin{tabular}{|l|l|l|l|}
\hline & $\begin{array}{l}\text { Preferred place } \\
\mathbf{N}(\%)\end{array}$ & $\begin{array}{l}\text { Preference met } \\
\text { N (proportion) }\end{array}$ & $\begin{array}{l}\text { 95\% CI } \\
\text { (binomial } \\
\text { exact) }\end{array}$ \\
\hline Home & $524(65.7 \%)$ & $307(.59)$ & $.54-.63$ \\
\hline Home for the elderly & $112(14.1 \%)$ & $103(.92)$ & $.85-.96$ \\
\hline Hospice or palliative care unit & $66(8.3 \%)$ & $53(.80)$ & $.69-.89$ \\
\hline Nursing home & $55(6.9 \%)$ & $54(.98)$ & $.90-1.00$ \\
\hline Hospital & $14(1.8 \%)$ & $14(1.00)$ & $.77-1.00$ \\
\hline $\begin{array}{l}\text { Institution for mental } \\
\text { healthcare }\end{array}$ & $5(0.6 \%)$ & $4(.80)$ & $.28-.99$ \\
\hline $\begin{array}{l}\text { Institution for mentally } \\
\text { disabled }\end{array}$ & $7(0.9 \%)$ & $6(.86)$ & $.42-1.00$ \\
\hline Other institution & $14(1.8 \%)$ & $10(.71)$ & $.42-.92$ \\
\hline Total & $797(100 \%)$ & $551(.69)$ & $.66-.72$ \\
\hline
\end{tabular}


Raijmakers, N.J.H., Veer, A.J.E. de, Zwaan, R., Hofstede, J., Francke, A.L. Which patients die in their preferred place? A secondary analysis of questionnaire data from bereaved relatives.

\begin{tabular}{|c|c|c|c|c|}
\hline 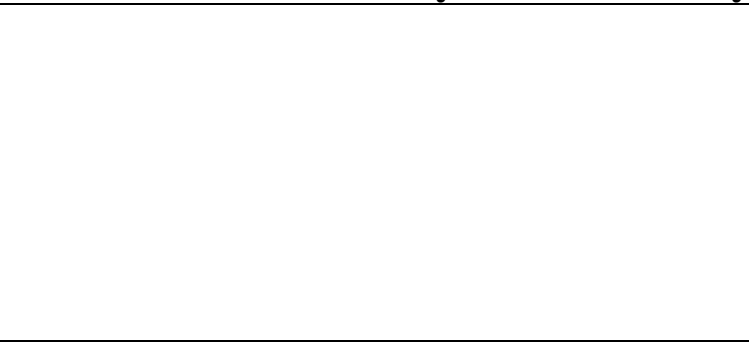 & $\begin{array}{l}\text { Death in } \\
\text { preferred } \\
\text { place } N(\%) \\
\mathbf{4 6 3}(66.0 \%)\end{array}$ & $\begin{array}{l}\text { Death } \\
\text { NOT in } \\
\text { preferre } \\
\text { d place } \\
\text { N }(\%) \\
239 \\
(34.0 \%) \\
\end{array}$ & OR & $90 \% \mathrm{CI}$ \\
\hline \multicolumn{5}{|l|}{ Individual factors } \\
\hline \multicolumn{5}{|l|}{ Sex } \\
\hline Man (ref) & $220(66.1 \%)$ & $\begin{array}{l}113 \\
(33.9 \%)\end{array}$ & & \\
\hline Woman & $243(65.9 \%)$ & $\begin{array}{l}126 \\
(34.1 \%)\end{array}$ & $\begin{array}{l}0.99 \\
1\end{array}$ & $0.762-1.288$ \\
\hline \multicolumn{5}{|l|}{ Age } \\
\hline$<75$ (ref) & $154(79.4 \%)$ & $\begin{array}{l}40 \\
(20.6 \%)\end{array}$ & & \\
\hline $75+$ & $292(59.8 \%)$ & $\begin{array}{l}196 \\
(40.2 \%)\end{array}$ & $\begin{array}{l}0.38 \\
7\end{array}$ & $0.278-0.538$ \\
\hline Being religious (ref $=$ not religious $)$ & $300(62.9 \%)$ & $\begin{array}{l}177 \\
(37.1 \%)\end{array}$ & $\begin{array}{l}0.63 \\
7\end{array}$ & $0.474-0.856$ \\
\hline \multicolumn{5}{|l|}{ Environmental factors } \\
\hline Having a partner (ref $=$ no partner) & $211(75.4 \%)$ & $\begin{array}{l}69 \\
(24.6 \%)\end{array}$ & $\begin{array}{l}2.06 \\
7\end{array}$ & $1.561-2.737$ \\
\hline \multicolumn{5}{|l|}{ Education level of bereaved relative } \\
\hline Low (ref) & $131(72.0 \%)$ & $\begin{array}{l}51 \\
(28.0 \%)\end{array}$ & & \\
\hline Middle & $38(80.9 \%)$ & $\begin{array}{l}9 \\
(19.1 \%)\end{array}$ & $\begin{array}{l}1.64 \\
4\end{array}$ & $0.843-3.204$ \\
\hline High & $35(81.4 \%)$ & $\begin{array}{l}8 \\
(18.6 \%)\end{array}$ & $\begin{array}{l}1.70 \\
3\end{array}$ & $0.846-3.428$ \\
\hline $\begin{array}{l}\text { Good health of bereaved relative (ref= poor } \\
\text { health) }\end{array}$ & $392(65.7 \%)$ & $\begin{array}{l}205 \\
(34.3 \%)\end{array}$ & $\begin{array}{l}0.85 \\
9\end{array}$ & $0.586-1.260$ \\
\hline \multicolumn{5}{|l|}{ Illness-related factors } \\
\hline \multicolumn{5}{|l|}{ Diagnoses } \\
\hline Cancer $($ ref $=$ no cancer $)$ & $252(76.6 \%)$ & $\begin{array}{l}77 \\
(23.4 \%)\end{array}$ & $\begin{array}{l}2.49 \\
7\end{array}$ & $1.897-3.287$ \\
\hline Stroke (ref=no stroke) & $44(52.4 \%)$ & $\begin{array}{l}40 \\
(47.6 \%)\end{array}$ & $\begin{array}{l}0.52 \\
0\end{array}$ & $0.353-0.765$ \\
\hline COPD (ref=no COPD) & $46(60.5 \%)$ & $\begin{array}{l}30 \\
(39.5 \%)\end{array}$ & $\begin{array}{l}0.76 \\
5\end{array}$ & $0.507-1.153$ \\
\hline Heart failure (ref=no heart failure) & $70(66.7 \%)$ & $\begin{array}{l}35 \\
(33.3 \%) \\
\end{array}$ & $\begin{array}{l}1.03 \\
3\end{array}$ & $0.714-1.494$ \\
\hline Dementia $($ ref $=$ no dementia $)$ & $80(48.2 \%)$ & $\begin{array}{l}86 \\
(51.8 \%)\end{array}$ & $\begin{array}{l}0.36 \\
9\end{array}$ & $0.273-0.498$ \\
\hline Presence of symptoms in week before death & & & & \\
\hline
\end{tabular}


Raijmakers, N.J.H., Veer, A.J.E. de, Zwaan, R., Hofstede, J., Francke, A.L. Which patients die in their preferred place? A secondary analysis of questionnaire data from bereaved relatives.

\begin{tabular}{|c|c|c|c|c|}
\hline Pain (ref= no pain) & $295(66.3 \%)$ & $\begin{array}{l}150 \\
(33.7 \%)\end{array}$ & $\begin{array}{l}1.12 \\
6\end{array}$ & $0.833-1.522$ \\
\hline Fatigue (ref $=$ no fatigue) & $388(66.3 \%)$ & $\begin{array}{l}197 \\
(33.7 \%)\end{array}$ & $\begin{array}{ll}1.04 \\
3\end{array}$ & $0.632-1.720$ \\
\hline Shortness of breath (ref $=$ no shortness of breath) & $242(64.0 \%)$ & $\begin{array}{l}136 \\
(36.0 \%) \\
\end{array}$ & $\begin{array}{l}0.79 \\
8\end{array}$ & $0.594-1.073$ \\
\hline Constipation $(\mathrm{ref}=$ no constipation $)$ & $166(67.2 \%)$ & $\begin{array}{l}81 \\
(32.8 \%) \\
\end{array}$ & $\begin{array}{l}1.05 \\
9\end{array}$ & $0.788-1.424$ \\
\hline Depressive mood $(\mathrm{ref}=$ no depressive $\operatorname{mood})$ & $238(62.8 \%)$ & $\begin{array}{l}141 \\
(37.2 \%)\end{array}$ & $\begin{array}{l}0.67 \\
7\end{array}$ & $0.503-0.912$ \\
\hline Anxiety (ref= no anxiety) & $226(64.2 \%)$ & $\begin{array}{l}126 \\
(35.8 \%)\end{array}$ & $\begin{array}{l}0.85 \\
5\end{array}$ & $0.641-1.139$ \\
\hline \multicolumn{5}{|l|}{ Care as perceived by bereaved relative } \\
\hline $\begin{array}{l}\text { Patient had GP contact in week before death } \\
\text { (ref=no contact) }\end{array}$ & $369(85.4 \%)$ & $\begin{array}{l}63 \\
(14.6 \%)\end{array}$ & $\begin{array}{l}10.9 \\
67\end{array}$ & $8.065-14.912$ \\
\hline Professionals had necessary expertise $(\mathrm{ref}=\mathrm{no})$ & $432(68.1 \%)$ & $\begin{array}{l}202 \\
(31.9 \%)\end{array}$ & $\begin{array}{l}3.20 \\
8\end{array}$ & $2.034-5.059$ \\
\hline $\begin{array}{l}\text { Professionals were informed about patient's } \\
\text { attitudes towards end-of-life decisions }(\text { ref }=\text { no) }\end{array}$ & $343(70.0 \%)$ & $\begin{array}{l}147 \\
(30.0 \%)\end{array}$ & $\begin{array}{l}1.75 \\
0\end{array}$ & $1.176-2.604$ \\
\hline $\begin{array}{l}\text { Professional support with preparations for saying } \\
\text { goodbye to relatives }(\mathrm{ref}=\text { no) }\end{array}$ & $251(70.5 \%)$ & $\begin{array}{l}105 \\
(29.5 \%)\end{array}$ & $\begin{array}{l}1.25 \\
8\end{array}$ & $0.768-2.060$ \\
\hline $\begin{array}{l}\text { Continuity of care by different professionals (ref } \\
=\text { no) }\end{array}$ & $428(69.0 \%)$ & $\begin{array}{l}192 \\
(31.0 \%)\end{array}$ & $\begin{array}{l}3.95 \\
2\end{array}$ & $2.491-6.268$ \\
\hline $\begin{array}{l}\text { Professionals took the personal wishes of the } \\
\text { patient into account }(\mathrm{ref}=\mathrm{no})\end{array}$ & $441(68.3 \%)$ & $\begin{array}{l}205 \\
(31.7 \%) \\
\end{array}$ & $\begin{array}{l}5.07 \\
1\end{array}$ & $2.947-8.725$ \\
\hline \multicolumn{5}{|c|}{$\begin{array}{l}\text { * The number of observations varies per variable due to missing data. See table } 2 \text { for number c } \\
\text { per variable } \\
\text { Italics and underlined gives the factors that are significant at } 0.10 \text { ( } 90 \% \mathrm{CI} \text { does not include } 1)\end{array}$} \\
\hline \multicolumn{5}{|c|}{$\begin{array}{l}\text { Cases of dying in a nursing home or hospital were left out in further analyses, because there was barely any } \\
\text { variance to be explained. Respondents whose loved one died in an institution for mental health care, mentally } \\
\text { disabled or other kind of institution }(n=26) \text { were also left out because of the particular context in which they } \\
\text { died. }\end{array}$} \\
\hline
\end{tabular}


Raijmakers, N.J.H., Veer, A.J.E. de, Zwaan, R., Hofstede, J., Francke, A.L. Which patients die in their preferred place? A secondary analysis of questionnaire data from bereaved relatives.

\begin{tabular}{|c|c|c|}
\hline \multicolumn{3}{|c|}{$\begin{array}{l}\text { Table 5: Multivariate model for dying in the preferred place: final model } \\
(\mathrm{n}=674)^{*}\end{array}$} \\
\hline & OR & $95 \% \mathrm{CI}$ \\
\hline \multicolumn{3}{|l|}{ Individual factors } \\
\hline \multicolumn{3}{|l|}{ Preferred place of dying } \\
\hline Home (ref = home for the elderly) & 0.053 & $0.023-0.120$ \\
\hline \multicolumn{3}{|l|}{ Environmental factors } \\
\hline Having a partner (ref=no partner) & 2.032 & $1.233-3.348$ \\
\hline \multicolumn{3}{|l|}{ Illness-related factors } \\
\hline \multicolumn{3}{|l|}{ Diagnosis } \\
\hline Stroke $($ ref $=$ no stroke $)$ & 0.505 & $0.261-0.976$ \\
\hline Dementia (ref=no dementia) & 3.333 & $1.010-11.000$ \\
\hline Dementia x preferred place is Home & 0.143 & $0.037-0.561$ \\
\hline \multicolumn{3}{|l|}{ Care as perceived by bereaved relative } \\
\hline $\begin{array}{l}\text { GP contact in the last week before death } \\
\text { (ref=no contact) }\end{array}$ & 3.849 & $1.375-10.776$ \\
\hline $\begin{array}{l}\text { GP contact in the last week before death } \mathrm{x} \\
\text { preferred place is Home }\end{array}$ & 6.477 & $2.005-20.921$ \\
\hline $\begin{array}{l}\text { Continuity in care by different professionals } \\
(\text { ref }=\text { no) }\end{array}$ & 4.826 & $2.356-9.886$ \\
\hline Nagelkerke R2 & & 0.562 \\
\hline $\begin{array}{l}\text { Chi-square model }(\mathrm{df}=6) \text { (Hosmer and } \\
\text { Lemeshow) }\end{array}$ & & 4.528 \\
\hline $\mathrm{P}$ value (Hosmer and Lemeshow) & & 0.606 \\
\hline
\end{tabular}

